\title{
Experimental Investigation on Properties and Machining Performance of CNT Suspended Vegetable oil Nanofluids
}

\author{
P. V. Krishna ${ }^{1 *}$, R. R. Srikant ${ }^{2}$ and N. Parimala ${ }^{1}$ \\ ${ }^{1}$ Department of Mechanical Engineering, NIT Warangal, Telangana, 506004, India \\ *Email: vamsikrishna@nitw.ac.in \\ Phone: +91 8332969371 \\ ${ }^{2}$ Department of Industrial Technology, University of Northern lowa, IA-50614, USA
}

\begin{abstract}
This work is motivated by environmentally conscious machining and focus on the basic properties and applicability of nano cutting fluids in machining. Cutting fluids are formulated by dispersing carbon nanotubes (CNT) in coconut oil (CC) with varying percentage of nanoparticle inclusions (NPI). The properties such as density, heat transfer coefficient, dynamic viscosity and thermal conductivity are determined before their application. The formulated nanofluids are applied during machining through minimum quantity lubrication (MQL) technique. Microbial contamination and biodegradability tests are conducted to assess the quality of nanocutting fluids. Viscosity is found to decrease with increase in temperature where, as specific heat slightly decreased with an increase in NPI for CNT dispersed fluids. It is observed that nanofluids in MQL upshot in the reduction of cutting force, cutting temperature, tool wear and surface roughness. CNT dispersed cutting fluids at $0.5 \% \mathrm{NPI}$ and speed of $60 \mathrm{~m} / \mathrm{min}, 0.131 \mathrm{~mm} / \mathrm{rev}$ feed and $0.5 \mathrm{~mm}$ depth of cut (DOC) shown better performance in the selected range of parameters. Machining performance is more influenced by the percentage of nanoparticles and then the depth of cut, speed and feed respectively. For the cutting conditions, the influence of DOC in obtaining minimum cutting forces and reducing cutting temperatures is found to be $85 \%$ and $45 \%$ respectively for nBA dispersed fluids. The extent of influence of $\%$ NPI is found to be $35.19 \%$ for CNT dispersed fluids to obtain reduced cutting forces, cutting temperatures, tool wear and surface roughness according to GRA analysis. Microbial contamination is observed to be the least for $0.5 \%$ NPI dispersed fluids. It is also identified that nano cutting fluids used in this work are biodegradable and biologically treatable for disposal as well.
\end{abstract}

Keywords: Vegetable oil; nanofluid; CNT; machining.

\section{INTRODUCTION}

Cutting fluids are a conventional method to reduce friction and temperatures in metal cutting. In the cutting zone, a small amount of heat is dissipated into the workpiece, tool and cutting fluid if used whereas the enormous amount of heat is carried away be the chip $[1,2]$. The non-usage of cutting fluid decreases the heat dissipation from the cutting zone resulting in increased tool and workpiece temperatures. Such high temperature causes dimensional errors of the workpiece, tool life reduction and also surface integrity of the workpiece [1-3].

Conventional cutting fluids usage is limited due to various environmental and health hazards associated. Cutting fluids cause various skin diseases such as mechanical 
trauma to the skin, infections, oil acne and allergic dermatitis $[4,5]$. Though biocides are one of the most promising solutions to encounter contamination [6], the waste disposal regulations of various government agencies across the globe make them prohibitive. Workers are found to be affected by lung, throat and nose diseases [7]. Ngoi and Sreejith [8] reported that cutting fluids hamper the environment and workers health. Apart from these disadvantages, the disposal of used oil is an added expense to the manufacturing process [9]. With the advent of Environmental Protection Agency (EPA), cutting fluid disposal has gained prominence. To eliminate the problems with exposure and disposal different strategies like using vegetable-based oils and Minimum Quantity Lubrication (MQL) have gained importance.

Ojolo et al. [10] investigated the role of different types of vegetable oils on cutting forces in machining of $\mathrm{MS}, \mathrm{Al}$ and $\mathrm{Cu}$ materials. Under varying cutting conditions cutting force was measured and inferred the suitability of vegetable oils in machining. In MQL approach, small quantities of fluid are used, typically less than $100 \mathrm{ml} / \mathrm{hour}$. This eliminates the problem of disposal and recycling. Diniz et al. [11] observed that there was a reduction in the flank wear and surface roughness under MQL mode than that of wet turning of SAE 52100 steel. MQL mode of operation resulted in improved surface integrity and reduction in thermal shocks that were induced in machining [12]. Results indicate that MQL enables a reduction in cutting force $(\mathrm{F})$, temperature $(\mathrm{T})$, tool wear $\left(\mathrm{V}_{\mathrm{b}}\right)$ and surface roughness $\left(\mathrm{R}_{\mathrm{a}}\right)$ along with favourable chip-tool interaction.

Some researchers added nanoparticles to the base fluids to enhance their properties and thus increase the efficacy of MQL [13-15]. Different particles like Boric Acid, CNT, graphite and $\mathrm{MoS}_{2}$ are used. The choice of nanoparticles depends on the application of the nanofluids. In applications like machining, where both cooling and lubrication are important, inclusions like boric acid, $\mathrm{MoS}_{2}, \mathrm{CNT}$ (carbon nanotubes) or graphite may be used. In the present work, CNT is chosen as suspensions in vegetable oil. CNTs are allotropes of carbon with a cylindrical nanostructure. Each tube is held at a certain distance from either of its neighbouring tubes by interatomic forces. Due to their high load-bearing capacities, CNTs are used in lubricants working under high-pressure conditions. To use the fluids, it is important to ascertain the basic properties.

Hegab el al. [16] investigated the effect of multi-walled CNTs (MWCNT) in machining Ti-6Al-4V to study the surface quality under varying speed, feed, depth of cut and nano-additives. They reported that $4 \%$ MWCNTs nanofluids decreased surface roughness by $38 \%$ compared to that of without nano additives, while $2 \%$ MWCNTs nanofluids improved the surface quality by $50 \%$. Hegab et al. [17] also investigated the tool performance and chip morphology using MWCNTs and $\mathrm{Al}_{2} \mathrm{O}_{3}$ nanofluids while machining Inconel 718 under MQL condition. It has been observed that MWCNT nanofluids showed better performance compared to $\mathrm{Al}_{2} \mathrm{O}_{3}$ nanofluids.

Yimin Xuan and Qiang Li et al. [18] inferred that nanofluids enhance the heat transfer process because of improved thermal conductivity. Thermal conductivity is also affected by other parameters affect. Krajnik et al. [19] analysed various aspects of tribology of nanofluids and concluded that conventional cutting fluids performance was lower compared to nanofluids in machining.

It is clear from the literature survey that nanofluids can be advantageously used as cutting fluids in MQL. Rahman et al. [20] investigated the effect of nanofluids dispersed with three different nanoparticles $\left(\mathrm{Al}_{2} \mathrm{O}_{3}, \mathrm{MoS}_{2}\right.$, rutile- $\left.\mathrm{TiO}_{2}\right)$ in Canola and extra virgin olive oils under MQL condition at different concentrations. They reported that nanofluids provided improved surface finish, reduced tool wear and lower cutting forces and temperatures. The thermo-physical properties, surface morphology, were also 
reported in work. However, very few works have been reported in this area. The present work attempts to investigate the machining performance of coconut oil-based CNT dispersed nanofluids under MQL condition at varying NPI by weight. The measurement of properties and sustainable aspects are also found in this work.

\section{METHODOLOGY}

\section{Measurement of Properties of Nanofluids}

Nanofluids are formulated by suspending CNT in coconut oil in varying proportions $(0.25 \%, 0.5 \%, 0.75 \%$, and $1 \%)$ by weight. Before carrying out further tests, the fluids are tested for stability using the sedimentation test [21]. The fluids were found to be stable for 24 hours. Also, all the fluids were found to have $\mathrm{pH}$ value in the range of 8-9.5 which is suitable for cutting fluids.

The density of CC and CC+CNT at varying NPI is measured using a hydrometer [ASTM D4052-96]. Viscosity is an important property affecting lubrication. In the current investigation, the viscosity of nanofluids was evaluated with Brookfield Viscometer [ASTM D2983-09]. The thermal conductivity of base fluids and nanofluids are evaluated at various temperatures using PA Hilton steady state apparatus [ASTMD2717-95]. The thermal conductivity of the samples is evaluated by using the Eq. (1) with the help of recorded temperatures.

$$
\mathrm{k}_{\mathrm{oil}}=\frac{\mathrm{Q}_{\mathrm{c}} \Delta \mathrm{r} \mathrm{A}}{\Delta \mathrm{t}}
$$

where $k_{\text {oil }}=$ thermal conductivity of the base fluid, $\mathrm{Q}_{\mathrm{c}}=$ conduction heat transfer through the air $(\mathrm{W}), \Delta \mathrm{r}=$ Radial clearance $(0.3$ in $\mathrm{m}), \mathrm{A}=$ Area of conducting path $\left(\mathrm{m}^{2}\right)$, and $\Delta \mathrm{t}=$ Temperature difference $(\mathrm{K})$.

An empirical relation is used to express the specific heat which is helpful in the later stage to estimate the convective coefficient oh heat transfer Eq. (2).

$$
\mathrm{C}_{\mathrm{pnf}}=\varnothing \mathrm{C}_{\mathrm{ps}}+(1-\varnothing) \mathrm{C}_{\mathrm{pf}}
$$

Where, $C_{\mathrm{pnf}}, \mathrm{C}_{\mathrm{nf}}$ and $\mathrm{C}_{\mathrm{pf}}$ are specific heats of nanofluid, base fluid and dispersed nanoparticles respectively. Heat transfer coefficient is significant in deciding the cooling abilities of a fluid. It is one of the essential thermal properties of nanofluids which influences the machining performance. Heat transfer coefficient is calculated by using Hilpert Eq. (3) for flow over cylinders, due to its analogy with turning process.

$$
\mathrm{Nu}=\mathrm{h} \times \frac{\mathrm{D}}{\mathrm{knf}}=\mathrm{C} .(\mathrm{Re}, \mathrm{Pr})
$$

where, Re - Reynolds's number, Pr - Prandtl number, h - heat transfer coefficient, $D$ workpiece diameter, $C$ and $m$ are constants that depend on the value of Re. 


\section{Microbial Contamination and Biodegradability Test}

These cutting fluids degrade with time because of microbial contamination which is its major limitation. The unchecked microbial growth results in problems like tool and workpiece corrosion, rancid odours, lubricity are lost, and there is delivery line plugging. When operators are exposed to these fluids, skin diseases and malfunction of lungs occur. In the current study, conventional cutting fluids and nano cutting fluids were tested for microbial contamination using the plate count method [22].

Biodegradability index indicates biodegradability of the fluids. This index is measured from Biochemical Oxygen Demand for 5 days (BOD5) and Chemical Oxygen Demand (COD) [23]. Biodegradability index (BI) = BOD5/COD.

i. If $\mathrm{BI}>0.6$, biodegradable, treated biologically.

ii. If $0.3<\mathrm{BI}<0.6$, seeding is required for biological treatment

iii. If $\mathrm{BI}<0.3$, biologically treatment not possible, chemical treatment is required

\section{Machining Performance}

CNT particles smaller than $100 \mathrm{~nm}$ were used to formulate nanofluids. CNT was suspended with $0.25 \%, 0.5 \%, 0.75 \%$ and $1 \%$ proportions on weight percentage basis. Nanofluids were prepared by manual stirring followed by sonication for $1 \mathrm{hr}$. $10 \mathrm{HP}$ precision lathe was used to perform the machining experiments. Cutting conditions were selected based on the tool-workpiece combination. AISI 1040 steel $(30 \pm 2$ HRC) was used as workpiece and carbide tools (CNMG120408NC6110) were used with PSLNR 2020 K12 tool holder. Machining was done at different lubrication conditions.

Comparative analysis with respect to these cutting fluid conditions was done to understand the efficacy of $\mathrm{CC}+\mathrm{CNT}$ fluids at constant cutting conditions cutting speed $(\mathrm{V})=60 \mathrm{~m} / \mathrm{min}$, feed rate $(\mathrm{f})=0.14 \mathrm{~mm} / \mathrm{rev}$ and depth of cut $(\mathrm{d})=0.5 \mathrm{~mm}$ at CNT inclusion of $0.25 \%$. For individual assessment of their performance (nCNT suspensions in CC oils) machining was carried out at various cutting conditions. Cutting conditions, workpiece, tool and MQL flow rate were chosen from the study [24]. Measurement of Cutting forces was made using a piezoelectric dynamometer (Model: Kistler, make: 9272) and embedded thermocouple technique was used to measure the cutting temperatures [19]. Apart from this, surface roughness was measured with Taylor Hobson surf tester, and tool flank wear was measured at regular intervals with an optical microscope (Mitutoyo).

\section{Optimisation using Taguchi Based Grey Relational Analysis}

Taguchi's experimental design, ANOM and ANOVA followed by Grey Relational Analysis were undertaken to examine the influence of nanofluids, NPI and cutting conditions on $\mathrm{F}, \mathrm{T}, \mathrm{R}_{\mathrm{a}}$ and $\mathrm{V}_{\mathrm{b}}$. Experiments were conducted as per $\mathrm{L}_{18}$ Orthogonal Array $(\mathrm{OA})$, and the experimental results were analysed using the Taguchi method to identify the optimal process parameters and its levels. $F, T, V_{b}$ and $R_{a}$ are the important performance characteristics in turning operation, and hence minimisation of these performance characteristics is considered as an objective function. Factors and levels which were chosen based on the literature for suspension of CNT in the base fluid are depicted in Table 1. In the current study, different levels of factors such as NPI, V, $\mathrm{f}$ and $\mathrm{d}$ were chosen. The assignment of the factors is made considering six levels ( 1 factor) and three levels (3 factors) to L18 OA for different suspensions of nCNT in the base fluid. 
Table 1. Selected factors at various levels.

\begin{tabular}{lcccccc}
\hline \multirow{2}{*}{ Factors } & \multicolumn{7}{c}{ Levels } \\
& 1 & 2 & 3 & 4 & 5 & 6 \\
\hline \% NPI (A) & 0 & 0.25 & 0.5 & 0.75 & 1 & 1.25 \\
V - m/min (B) & 60 & 80 & 100 & NIL & NIL & NIL \\
f - mm/rev (C) & 0.131 & 0.161 & 0.191 & NIL & NIL & NIL \\
d - mm (D) & 0.5 & 0.75 & 1 & NIL & NIL & NIL \\
\hline
\end{tabular}

\section{RESULTS AND DISCUSSION}

\section{Properties of Nanofluids}

It is observed from Table 2 that there is an enhancement in the effective density of nanofluids from $0 \%$ to higher NPI. Viscosity is used to assess the behaviour of nanofluids more prominently in machining when they are employed as cutting fluids in machining. Experimental values of dynamic viscosity are estimated by Brookfield viscometer. Temperature range of measuring viscosity is $30^{\circ} \mathrm{C}-60^{\circ} \mathrm{C}$ to find its variation with temperature. From Table 2, it is found that viscosity decrease with temperature rise while there is an increasing trend with higher NPI for all the base fluid and nanoparticle combinations. The high intermolecular force of attraction between the nanofluid molecules decreases with increase in temperature leading to the reduction in viscosity. Enhancement in viscosity is observed as NPI increases due to high intermolecular forces of attraction.

The thermal conductivity of the samples was measured to assess the cooling capabilities of the fluids. Since metals are of high thermal conductivity than that of fluids, suspending metallic nanoparticles into the base fluid is expected in enhancing the thermal conductivity of the fluid. The thermal conductivity of vegetable oil-based nanofluids at varying NPI measured is shown. It may be seen that the thermal conductivity of nanofluids is found to be increased with NPI.

There is a slight increase in specific heat with an increase in NPI from 0 to 1.25 $\%$. This increase cannot be attributed to the Brownian motion of nanoparticles as it is not a transport property. This effect may be caused by the formation of nanoparticles' film in conjunction with the base fluid. Since specific heat of a nanofluid signifies its heat storage capacity, higher the enhancement lower is the capacity of heat dissipation of a fluid. Larger specific surface energy leads to the increase in specific heat capacity of nanoparticle (in comparison to bulk material).

The results for the coefficient of heat transfer are shown in Table 2. Coefficient of heat transfer increased with NPI for nanofluids under test. Enhancement in heat transfer is due to increased kinematic viscosity, effective density and thermal conductivity of nanofluids with an increase in NPI. Brownian motion and bulk motion of the fluid are responsible for the enhancement of coefficient of heat transfer of the nanofluid. It can be concluded that while increasing the NPI heat transfer coefficient increases for carbon nanotubes with varying NPI. 
Table 2. Properties of nanofluids.

\begin{tabular}{|c|c|c|c|c|c|c|c|}
\hline \multirow{2}{*}{\multicolumn{2}{|c|}{ Properties }} & \multicolumn{6}{|c|}{ Basefluid (+CNT) samples } \\
\hline & & CNT1 & CNT2 & CNT3 & CNT4 & CNT5 & CNT6 \\
\hline \multirow{3}{*}{\multicolumn{2}{|c|}{$\begin{array}{l}\text { Density }\left(\mathrm{g} / \mathrm{cm}^{3}\right) \\
\text { Specific heat }(\mathrm{J} / \mathrm{kg}-\mathrm{k}) \\
\text { Heat transfer } \\
\text { coefficient }\left(\mathrm{W} / \mathrm{m}^{2} \mathrm{~K}\right) \\
\text { at } 60 \mathrm{~m} / \mathrm{min} \text { speed }\end{array}$}} & 0.99 & 0.991 & 0.992 & 0.993 & 0.994 & 0.997 \\
\hline & & 3972.9 & 3973.03 & 3973.16 & 3973.3 & 3973.43 & 3973.56 \\
\hline & & 16304.5 & 17066 & 17418.1 & 17082.8 & 17288.6 & 17607.7 \\
\hline \multirow{8}{*}{$\begin{array}{l}\text { Dynamic } \\
\text { viscosity }(\mathrm{cP}) \\
\text { at various } \\
\text { temperatures } \\
\left({ }^{\circ} \mathrm{C}\right)\end{array}$} & 25 & 0.78 & 0.85 & 0.95 & 1.05 & 1.07 & 1.14 \\
\hline & 30 & 0.77 & 0.83 & 0.93 & 0.98 & 1.01 & 1.08 \\
\hline & 35 & 0.73 & 0.79 & 0.87 & 0.9 & 0.95 & 1.01 \\
\hline & 40 & 0.65 & 0.73 & 0.82 & 0.88 & 0.91 & 0.95 \\
\hline & 45 & 0.6 & 0.67 & 0.75 & 0.81 & 0.86 & 0.92 \\
\hline & 50 & 0.54 & 0.58 & 0.63 & 0.65 & 0.72 & 0.87 \\
\hline & 55 & 0.50 & 0.55 & 0.60 & 0.63 & 0.7 & 0.78 \\
\hline & 60 & 0.30 & 0.34 & 0.37 & 0.41 & 0.43 & 0.52 \\
\hline \multirow{8}{*}{$\begin{array}{l}\text { Thermal } \\
\text { conductivity } \\
(\mathrm{W} / \mathrm{m} \mathrm{K}) \text { at } \\
\text { various } \\
\text { temperatures } \\
\left({ }^{\circ} \mathrm{C}\right)\end{array}$} & 25 & 0.54 & 0.605 & 0.623 & 0.658 & 0.672 & 0.687 \\
\hline & 30 & 0.56 & 0.614 & 0.658 & 0.643 & 0.653 & 0.708 \\
\hline & 35 & 0.575 & 0.618 & 0.656 & 0.668 & 0.676 & 0.721 \\
\hline & 40 & 0.582 & 0.651 & 0.674 & 0.693 & 0.674 & 0.701 \\
\hline & 45 & 0.595 & 0.668 & 0.691 & 0.704 & 0.704 & 0.714 \\
\hline & 50 & 0.603 & 0.662 & 0.68 & 0.684 & 0.684 & 0.742 \\
\hline & 55 & 0.608 & 0.666 & 0.674 & 0.721 & 0.701 & 0.742 \\
\hline & 60 & 0.615 & 0.679 & 0.714 & 0.711 & 0.732 & 0.764 \\
\hline
\end{tabular}

\section{Microbial Contamination}

Results for plate count of the fluids are presented in Table 3. It may be noted that $0.25 \%$ inclusion gives the least contamination. This may be due to the better stability of the nanofluids with this content of inclusions.

Table 3. Microbial contamination of nanofluids.

\begin{tabular}{lcccccc}
\hline Time & & \multicolumn{2}{c}{ Samples } \\
(in week) & CNT1 & CNT2 & CNT3 & CNT4 & CNT5 & CNT6 \\
\hline 1 & 40 & 10 & 25 & 60 & 80 & 90 \\
2 & 60 & 25 & 40 & 70 & 110 & 125 \\
3 & 75 & 30 & 75 & 85 & 135 & 143 \\
4 & 85 & 50 & 80 & 95 & 150 & 165 \\
\hline
\end{tabular}

\section{Biodegradability}

It can be seen that the biodegradability index increased with the inclusion of nanoparticles in CNT nanofluids (Table 4). However, since in all cases, BOD/COD ratio is less than 0.5 , which indicates that both the nanofluids are not readily biodegradable. However, since the fluids with inclusions have the value between $0.2-0.5$, they are biodegradable after treatment. 
Table 4. Biodegradability of nanofluids.

\begin{tabular}{lcccccc}
\hline \multirow{2}{*}{ Biodegradability } & \multicolumn{9}{c}{ Sample } \\
& CNT1 & CNT 2 & CNT 3 & CNT 4 & CNT 5 & CNT 6 \\
\hline BOD & 2.29 & 5.78 & 6.11 & 6 & 5.85 & 6 \\
COD & 1.31 & 1.82 & 1.65 & 1.43 & 1.33 & 1.3 \\
BOD/COD & 0.17 & 0.32 & 0.37 & 0.42 & 0.44 & 0.46 \\
\hline
\end{tabular}

\section{Machining at Constant Conditions}

Constant cutting conditions of $\mathrm{V}=60 \mathrm{~m} / \mathrm{min}, \mathrm{f}=0.14 \mathrm{~mm} / \mathrm{rev}$ and $\mathrm{d}=0.5 \mathrm{~mm}$ were selected. MQL rate of $10 \mathrm{~mL} / \mathrm{min}$ and $1 \mathrm{~L} / \mathrm{min}$ for flood lubrication were considered. From Figure 1 , it may be seen that in all the parameters considered, dry machining has the least performance. In case of cutting forces, tool wear and surface finish, MQL outperform flood lubrication. In case of temperatures, flood lubrication is slightly better, compared to MQL with either of the fluids. Since in all the cases, MQL is better, further study in this research is concentrated on MQL.

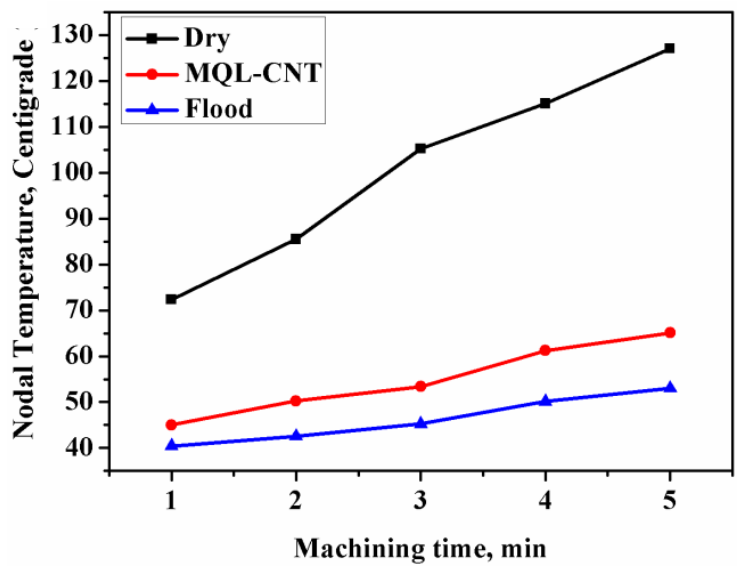

(a)

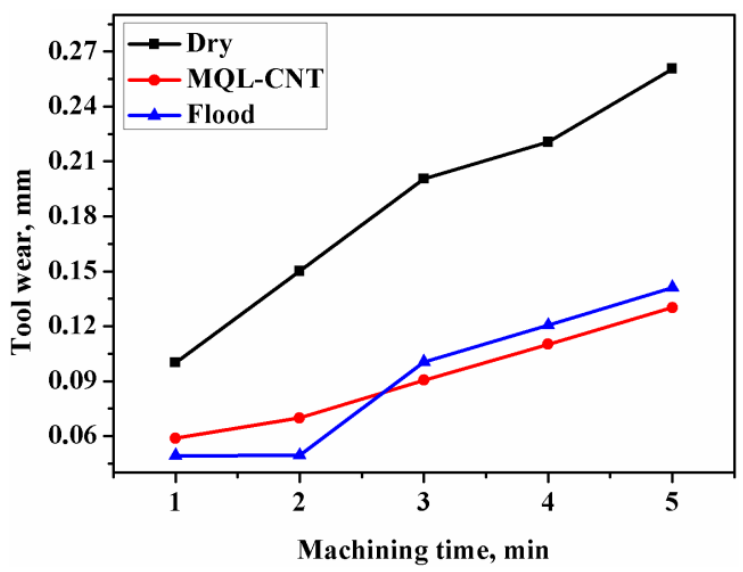

(c)

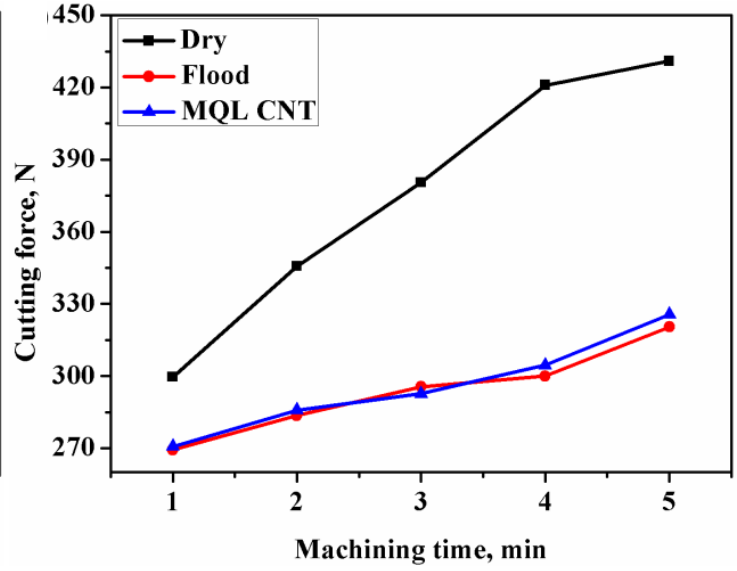

(b)

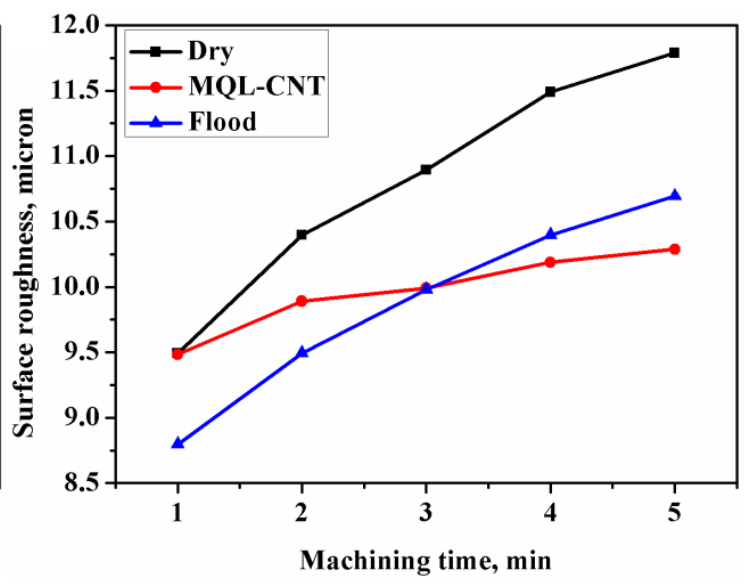

(d)

Figure1. Variation of (a) nodal temperatures; (b) cutting forces; (c) tool wear; (d) surface roughness responding to machining time at different machining conditions. 


\section{Grey Relational Analysis (GRA)}

The values considered, the responses obtained at each level and $\mathrm{S} / \mathrm{N}$ ratio of each factor are shown in Table 5. NPI, $\mathrm{V}, \mathrm{d}$ and $\mathrm{f}$ are considered as input parameters. ANOM and ANOVA techniques are implemented to examine the influence of inputs on responses. This work deals with the optimisation of output parameters of machining. This is done by finding $\mathrm{S} / \mathrm{N}(\mathrm{dB})$ ratio considering smaller the better criteria. $\mathrm{S} / \mathrm{N}$ ratios are obtained through the relation as shown in Eq. (4).

$$
\frac{\mathrm{S}}{\mathrm{N}} \text { ratio=-10 } \log \left(1 / \mathrm{n}_{\mathrm{f}}\right) \sum \mathrm{Y}_{\mathrm{ij}}^{2}
$$

\section{Cutting Force}

Figure 2 shows the factors effect on the main cutting force with nano cutting fluids. Coconut oil $+0.5 \% \mathrm{CNT}$ at V of $60 \mathrm{~m} / \mathrm{min}$ and a feed of $0.131 \mathrm{~mm} / \mathrm{rev}$ with a depth of cut of $0.50 \mathrm{~mm}$ are the optimal cutting parameters for the minimum cutting force. The order of the parameters is given according to their influence on the main cutting force as $\mathrm{d}, \mathrm{f}, \mathrm{V}$ and NPI shown in Table 6 . At $60 \mathrm{~m} / \mathrm{min}$ speed, coconut oil with $0.5 \%$ NPI performed well due to the higher thermal conductivity of CNT and stable film formation of coconut oil. During machining, severe stresses are induced in the workpiece. Plastic deformation occurs which imparts high compressive and frictional stresses at the tool face, which develop a cutting force in the cutting direction. Coconut is edible oil with fatty acids of triglyceride esters.

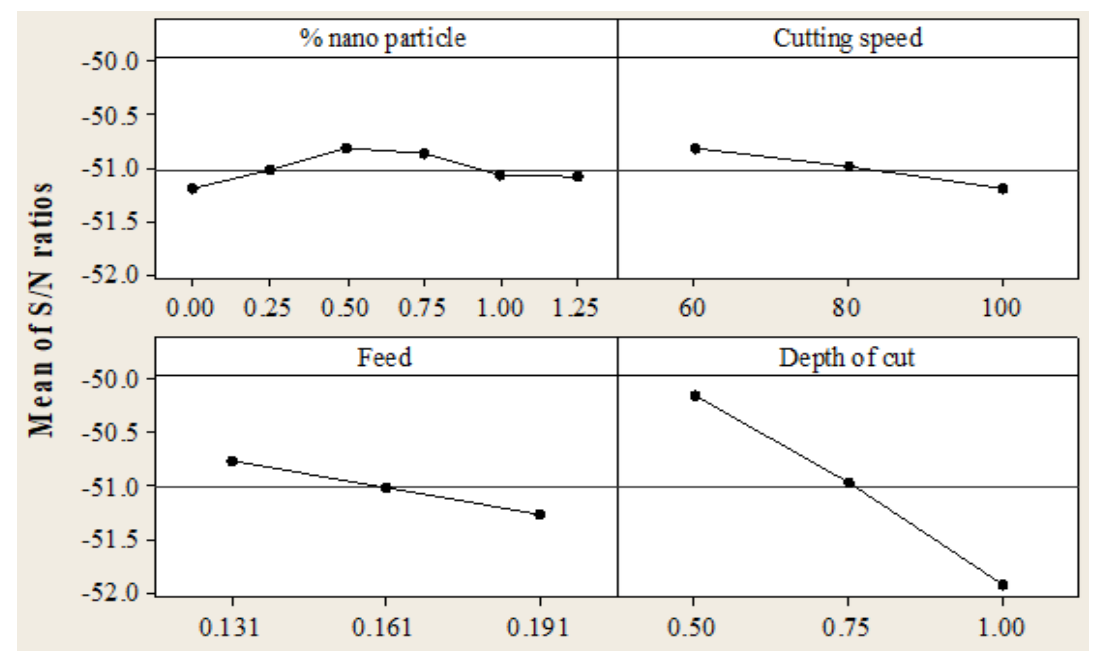

Figure 2. Main effects plot for $\mathrm{S} / \mathrm{N}$ ratio of main cutting force.

The polar-CO-O- group is bonded to triglyceride structure through ester linkage in vegetable oils. Coconut oil is stable at high temperature due to strong intermolecular interactions and is suited for machining at high temperature. The MQL nano-fluid mechanism plays a major role in enhancing the machining performance. The nano-cutting fluid is atomised into the MQL nozzle by using compressed air. It comes out as a very fine mist. This mist can easily penetrate the cutting zone between the tool and workpiece as their velocity is high. 


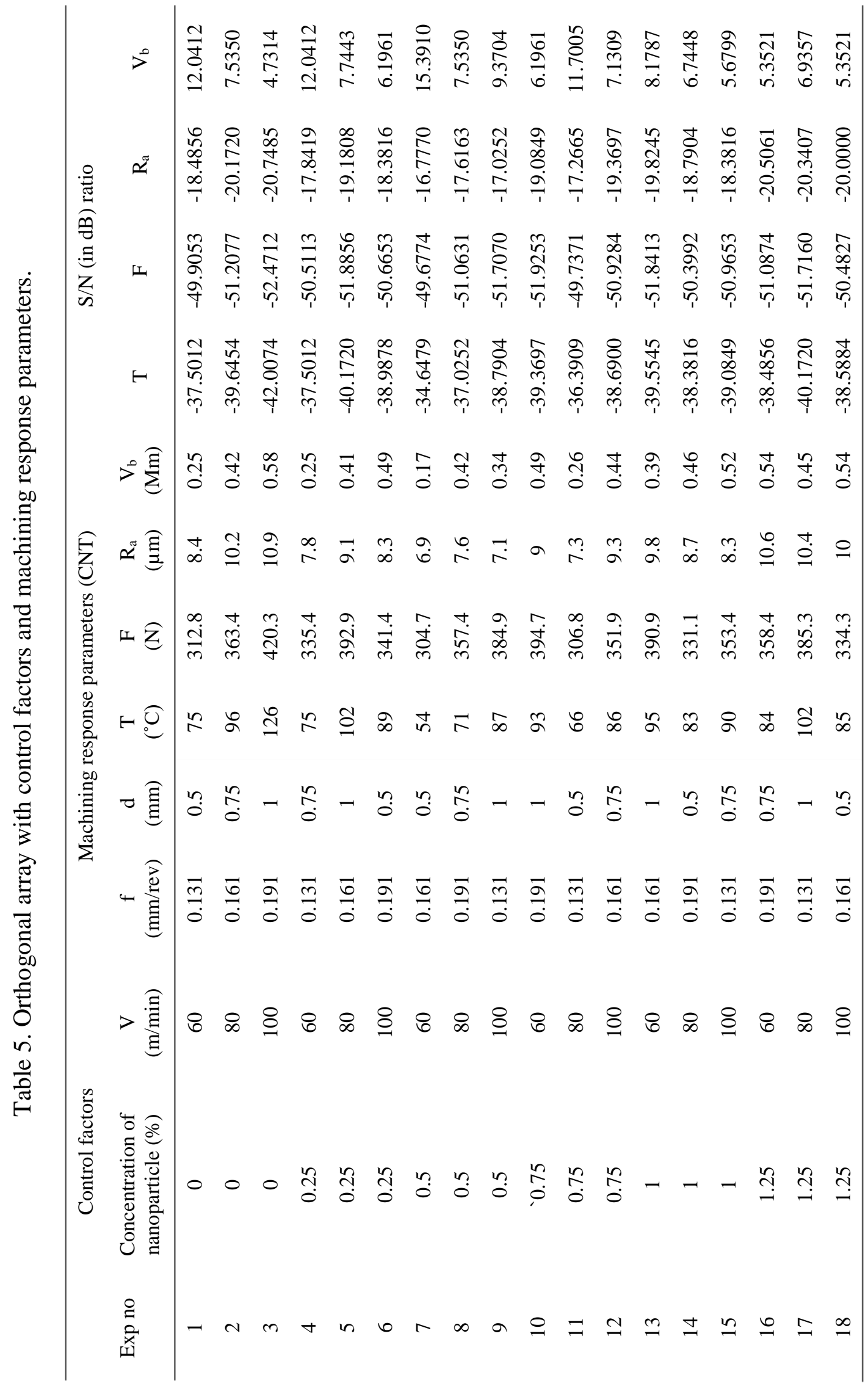


These droplets are formed on the tool and workpiece, and a thin film is formed thus improving the tribological properties and reducing the friction [16]. The reduced friction causes the cutting forces to decrease as the resistivity at the interface decreases. The use of coconut oil reduces cutting forces. Due to $90 \%$ of medium chain saturated fatty acids, coconut oil forms a stable lubricating film with metallic contact surfaces. At $0.50 \%$ NPI a speed of $60 \mathrm{~m} / \mathrm{min}$ imparts sufficient viscosity, and less coefficient of friction, in turn, reduced the cutting forces. The contribution of NPI, V, $\mathrm{f}, \mathrm{d}$ in reducing cutting force is $2.81 \%, 3.88 \%, 7.07 \%$ and $85.77 \%$ as seen from Table 7 .

Table 6. Response table for cutting force ( $\mathrm{S} / \mathrm{N}$ ratios).

\begin{tabular}{lcccc}
\hline \multirow{2}{*}{ Levels } & \multicolumn{2}{c}{ Factors } & $\mathrm{D}$ \\
\hline 1 & Nanoparticle & $\mathrm{V}$ & $\mathrm{f}$ & -50.14 \\
2 & -51.19 & -50.82 & -50.76 & -50.96 \\
3 & -51.02 & -51.00 & -51.00 & -51.92 \\
4 & -50.82 & -51.20 & -51.27 & -- \\
5 & -50.86 & -- & -- & -- \\
6 & -51.07 & -- & -- & - \\
Delta & -51.10 & -- & -- & 1.78 \\
Rank & 0.38 & 0.38 & 0.51 & 1 \\
Optimal & 3 & 4 & 2 & \\
\hline
\end{tabular}

Table 7. S/N data for main cutting force using ANOVA.

\begin{tabular}{lccccc}
\hline Factors & DOF & $\begin{array}{c}\text { Sum of } \\
\text { squares }\end{array}$ & $\begin{array}{c}\text { Mean } \\
\text { squares }\end{array}$ & $\begin{array}{c}\text { Variance } \\
\text { ratio }\end{array}$ & $\begin{array}{c}\text { Contribution } \\
(\mathrm{p})\end{array}$ \\
\hline \% nanoparticle & 5 & 0.3123 & 0.0625 & 7.20 & 2.81 \\
V & 2 & 0.4307 & 0.2154 & 24.84 & 3.88 \\
f & 2 & 0.7855 & 0.3927 & 45.30 & 7.07 \\
d & 2 & 9.5259 & 4.7629 & 549.44 & 85.77 \\
Error & 6 & 0.0520 & 0.0087 & & 0.47 \\
Total & 17 & 11.1064 & & & 100.00 \\
\hline
\end{tabular}

\section{Cutting Temperature}

The ability of coconut oil to form stable film due to its molecular arrangement reduces friction coefficient. Viscosity increase of the nanofluids results in nano lubricant film formation that separates the contact surface. However, beyond $0.5 \%$ NPI further increase in viscosity leads to the uneven spread of the lubricant film at surfaces in contact. This results in increasing temperatures due to increasing friction coefficient at higher NPI. High thermal conductivity CNT dispersions help in reducing cutting temperatures. Effect of process parameters on temperature is presented in Figure 3. The droplets formed due to MQL mechanism are on the tool and workpiece, and a thin film is formed. A thin film at the tool-workpiece interface that dissipates the heat generated in the cutting zone because of the improved thermal conductivity of the mist due to the presence of nanoparticles. Better heat dissipation leads to reduced cutting temperatures. The order of most influencing parameters and their contribution in reducing cutting temperatures are shown in Table 8 and Table 9. NPI contributes by $33.95 \%$ followed by cutting speed of 
$15.29 \%$, feed contributes by $4.37 \%$, and depth of cut contributes by $45.70 \%$ in reducing cutting temperatures.

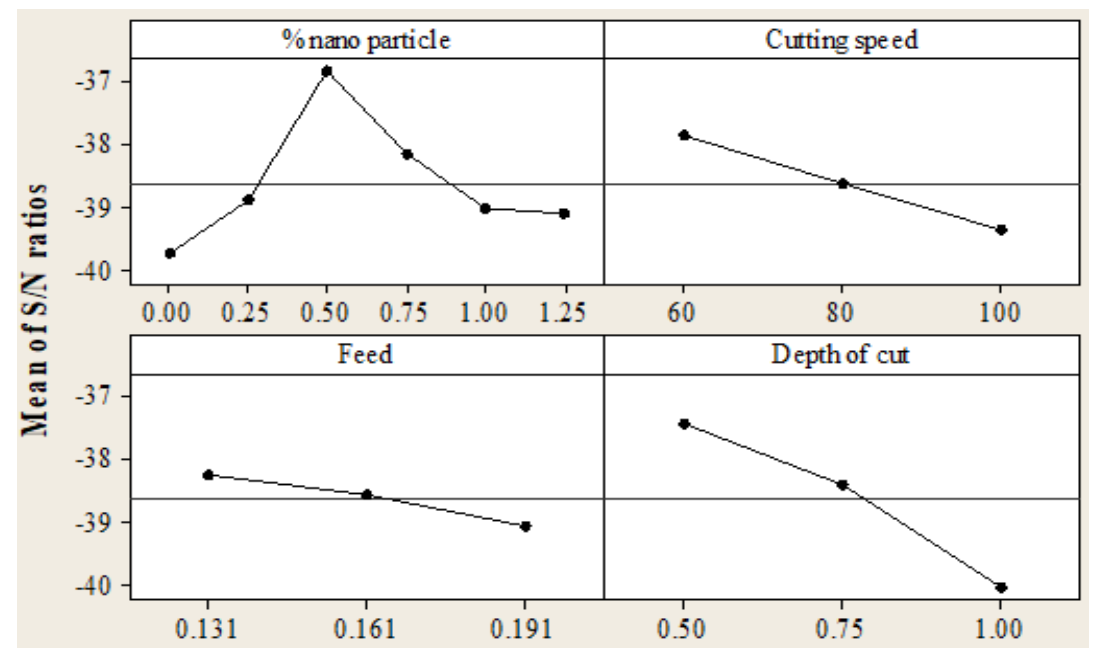

Figure 3. Main effects plot for $\mathrm{S} / \mathrm{N}$ ratios of temperature.

Table 8. Response table for temperature ( $\mathrm{S} / \mathrm{N}$ ratios).

\begin{tabular}{lcccc}
\hline \multirow{2}{*}{ Levels } & & \multicolumn{2}{c}{ Factors } & DOC \\
\hline 1 & Nanoparticle & $\mathrm{V}$ & $\mathrm{f}$ & -37.42 \\
2 & -39.72 & -37.84 & -38.24 & -38.41 \\
3 & -38.89 & -38.63 & -38.55 & -40.01 \\
4 & -36.82 & -39.36 & -39.04 & -- \\
5 & -38.15 & -- & -- & -- \\
6 & -39.01 & -- & -- & -- \\
Delta & -39.08 & -- & -- & 2.59 \\
Rank & 2.90 & 1.51 & 0.80 & 2 \\
Optimal & 1 & 3 & 4 & \\
\hline
\end{tabular}

Table 9. ANOVA for temperature (S/N data).

\begin{tabular}{lccccc}
\hline Factors & DOF & $\begin{array}{c}\text { Sum of } \\
\text { squares }\end{array}$ & $\begin{array}{c}\text { Mean } \\
\text { squares }\end{array}$ & $\begin{array}{c}\text { Variance } \\
\text { ratio }\end{array}$ & $\begin{array}{c}\text { \% Contribution } \\
(\mathrm{p})\end{array}$ \\
\hline \% Nanoparticle & 5 & 15.2887 & 3.0577 & 58.96 & 33.95 \\
V & 2 & 6.8875 & 3.4437 & 66.40 & 15.29 \\
$\mathrm{f}$ & 2 & 1.9670 & 0.9835 & 18.96 & 4.37 \\
$\mathrm{~d}$ & 2 & 20.5776 & 10.2888 & 198.39 & 45.70 \\
Error & 6 & 0.3112 & 0.0519 & & 0.69 \\
Total & 17 & 45.0320 & & & 100.00 \\
\hline
\end{tabular}

\section{Tool Wear}

Effect of process parameters on tool wear is shown in Figure 4, CC with $0.5 \%$ CNT at $\mathrm{V}=60 \mathrm{~m} / \mathrm{min}$ along with $\mathrm{f}$ and $\mathrm{d}$ be $0.131 \mathrm{~mm} / \mathrm{rev}$ and $0.50 \mathrm{~mm}$ respectively are more 
effectual process parameters in the reduction of tool wear (Table 10). The contribution of each factor on flank wear of tool from ANOVA analysis is shown in Table 11. NPI contributes by $29.16 \%$ while cutting speed contributes to the extent of $25.05 \%$ in tool wear reduction. Feed and depth of cut contribute by $26.97 \%$ and $13.80 \%$ respectively in reducing the tool wear. Stable film formation due to saturated fatty acid and medium chain fatty acid in coconut oil, reduction of the coefficient of friction decreasing the plastic contacts between tool-work interface and result in lower shear resistance between metallic surfaces. This phenomenon is more dominant in nanofluids due to their large surface to volume ratio.

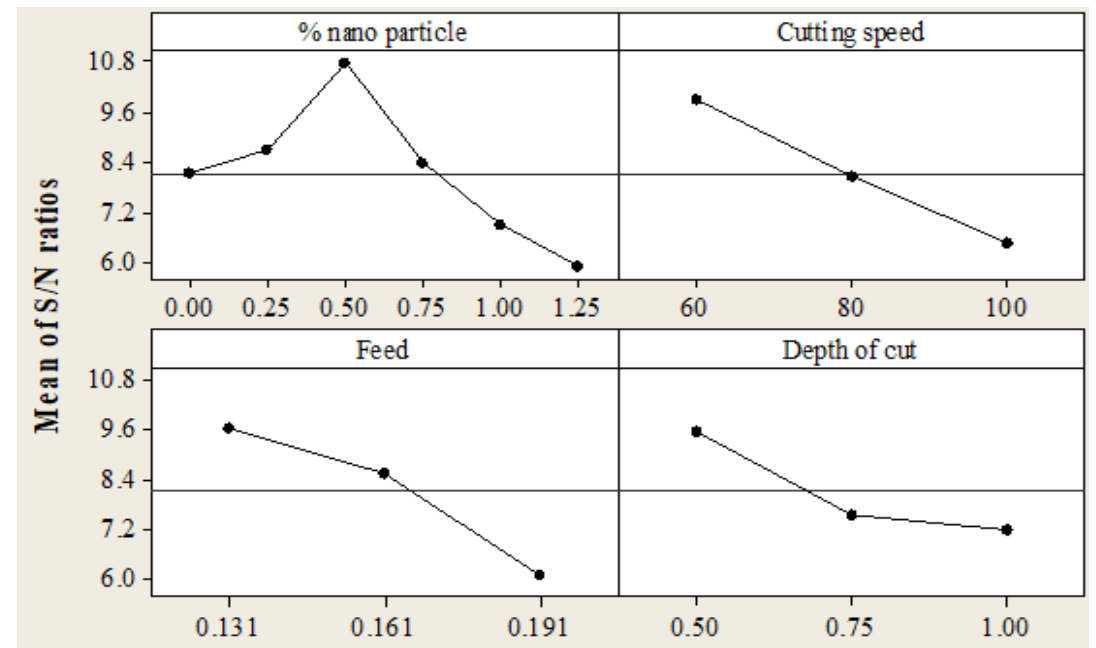

Figure 4. Main effects plot for $\mathrm{S} / \mathrm{N}$ ratios of tool wear.

Table 10. Response table for tool wear ( $\mathrm{S} / \mathrm{N}$ ratios).

\begin{tabular}{lcccc}
\hline \multirow{2}{*}{ Levels } & & \multicolumn{2}{c}{ Factors } & DOC \\
\hline 1 & Nanoparticle & $\mathrm{V}$ & $\mathrm{f}$ & 9.571 \\
2 & 8.103 & 9.867 & 9.628 & 7.546 \\
3 & 8.661 & 8.033 & 8.555 & 7.193 \\
4 & 10.765 & 6.410 & 6.126 & -- \\
5 & 8.343 & -- & -- & -- \\
6 & 6.868 & -- & -- & -- \\
Delta & 5.880 & -- & -- & 2.378 \\
Rank & 4.885 & 3.457 & 3.502 & 4 \\
Optimal & 1 & 3 & 2 & \\
\hline
\end{tabular}

As discussed earlier, the thin film at the tool-workpiece interface that dissipates the heat generated in the cutting zone because of the improved thermal conductivity of the mist due to the presence of nanoparticles. Better heat dissipation leads to reduced tool wear. The thermal conductivity increases with an increase in NPI which carry away the heat from the cutting zone. This leads to reduced cutting temperatures that decrease the softening of the tool material, thus reducing the tool wear. But beyond $0.5 \%$, though the thermal conductivity increases, there is an increase in the viscosity leading to the uneven formation of the oil film, increasing the friction that results in high cutting temperatures. 
This increases the tool wear beyond $0.5 \%$ NPI. These aspects converge to reduce the tool wear, which is found to be more significant at $0.5 \%$ NPI.

Table 11. ANOVA for tool wear (S/N Data).

\begin{tabular}{lccccc}
\hline Factors & DOF & $\begin{array}{c}\text { Sum of } \\
\text { squares }\end{array}$ & $\begin{array}{c}\text { Mean } \\
\text { squares }\end{array}$ & $\begin{array}{c}\text { Variance } \\
\text { ratio }\end{array}$ & $\begin{array}{c}\text { \% contribution } \\
(\mathrm{p})\end{array}$ \\
\hline \% Nanoparticle & 5 & 41.773 & 8.355 & 6.96 & 29.16 \\
V & 2 & 35.888 & 17.944 & 14.96 & 25.05 \\
$\mathrm{f}$ & 2 & 38.638 & 19.319 & 16.11 & 26.97 \\
$\mathrm{~d}$ & 2 & 19.764 & 9.882 & 8.24 & 13.80 \\
Error & 6 & 7.197 & 1.200 & & 5.02 \\
Total & 17 & 143.260 & & & 100.00 \\
\hline
\end{tabular}

\section{Surface Roughness}

$\mathrm{CC}$ with $0.5 \% \mathrm{CNT}$ at a $\mathrm{V}$ of $60 \mathrm{~m} / \mathrm{min}$ along with $\mathrm{f} 0.131 \mathrm{~mm} / \mathrm{rev}$ and $\mathrm{d}$ of $0.50 \mathrm{~mm}$ reduced surface roughness more compared to other cases (Figure 5). The contribution of each factor on the output response is shown in Tables 12 and Table 13 . CNT at $0.5 \%$ might be executing lower shear resistance between contact surfaces resulting in a lower value of friction coefficient. This is due to saturated medium chain fatty acids of coconut oil which helps to form stable film formation. The high thermal conductivity of CNT also helps in lowering the cutting temperatures. As mentioned earlier, better heat dissipation takes place due to MQL nanofluid which leads to reduced tool wear and cutting temperatures. This results in enhanced surface integrity and improved machining performance. Low cutting forces and temperatures impart good surface finish in machining.

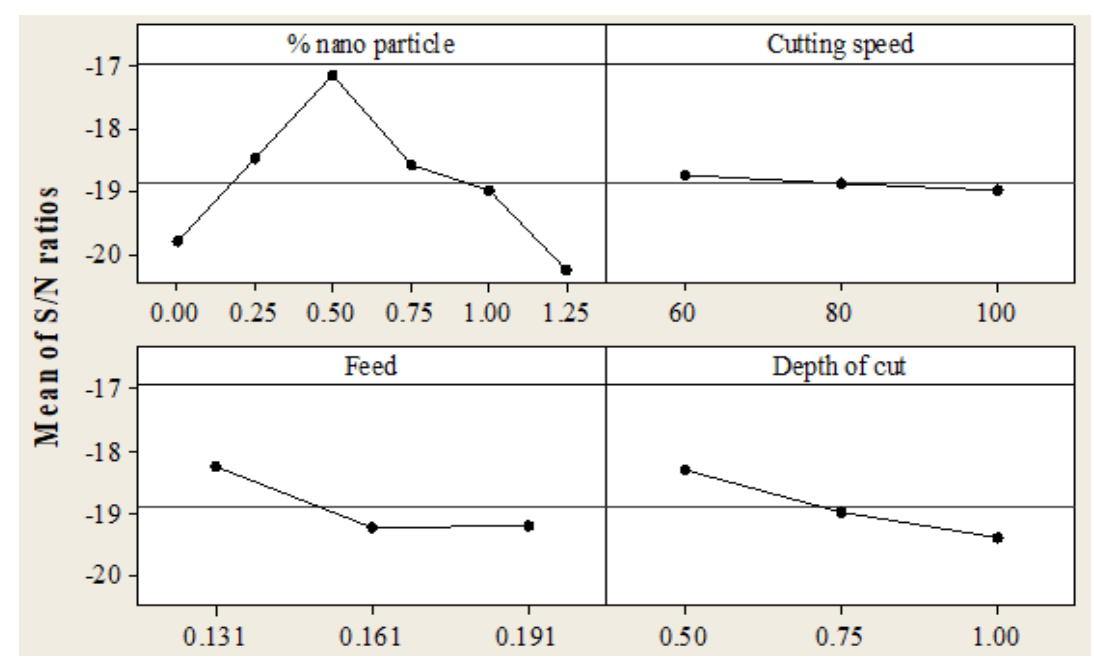

Figure 5. Main effects plot for $\mathrm{S} / \mathrm{N}$ ratios of surface roughness. 
Table 12. Response table for surface roughness (S/N ratios).

\begin{tabular}{lcccc}
\hline \multirow{2}{*}{ Levels } & & \multicolumn{2}{c}{ Factors } & DOC \\
\hline 1 & Nanoparticle & $\mathrm{V}$ & $\mathrm{f}$ & -18.28 \\
2 & -19.80 & -18.75 & -18.22 & -18.98 \\
3 & -18.47 & -18.89 & -19.22 & -19.37 \\
4 & -17.14 & -18.98 & -19.19 & -- \\
5 & -18.57 & -- & -- & -- \\
6 & -19.00 & -- & -- & - \\
Delta & -20.28 & -- & -- & 1.08 \\
Rank & 3.14 & 0.23 & 1.00 & 2 \\
Optimum & 1 & 4 & 3 & \\
\hline
\end{tabular}

Table 13. ANOVA for surface roughness (S/N Data).

\begin{tabular}{lccccc}
\hline Factors & DOF & $\begin{array}{c}\text { Sum of } \\
\text { squares }\end{array}$ & $\begin{array}{c}\text { Mean } \\
\text { squares }\end{array}$ & $\begin{array}{c}\text { Variance } \\
\text { ratio }\end{array}$ & $\begin{array}{c}\text { \% Contribution } \\
(\mathrm{p})\end{array}$ \\
\hline \% Nanoparticle & 5 & 18.3706 & 3.6741 & 87.15 & 69.96 \\
V & 2 & 0.1628 & 0.0814 & 1.93 & 0.62 \\
$\mathrm{f}$ & 2 & 3.8507 & 1.9254 & 45.67 & 14.66 \\
$\mathrm{~d}$ & 2 & 3.6218 & 1.8109 & 42.95 & 13.79 \\
Error & 6 & 0.2530 & 0.0422 & & 0.97 \\
Total & 17 & 26.2589 & & & 100.00 \\
\hline
\end{tabular}

\section{Process Parameters Optimisation using Grey Relational Analysis}

GRA deals with the conversion of actual responses $\left(F_{z}, T, T_{w}\right.$ and $\left.R_{a}\right)$ as shown in Table 15 to the values which are obtained by calculating $\mathrm{S} / \mathrm{N}$ ratios. These values are then normalised for responses using smaller-the better criterion. The formula used for the calculation of normalised values is shown in Eq. (5).

$$
x_{i}(k)=\frac{\max y_{i}(k)-y_{i}(k)}{\max y_{i}(k)-\min y_{i}(k)}
$$

Where $\mathrm{y}_{\mathrm{i}}(\mathrm{k})$ is the response value $\left(\mathrm{F}_{\mathrm{z}}, \mathrm{T}, \mathrm{T}_{\mathrm{w}}\right.$ and $\left.\mathrm{R}_{\mathrm{a}}\right)$, and $\mathrm{x}_{\mathrm{i}}(\mathrm{k})$ - normalised value for eachy ${ }_{i}(k)$. The normalised values of signal to noise ratios for $F_{z}, T, T_{w}$ and $R_{a}$ obtained using Eq. (5) are shown in Table 14. In this optimisation process, calculations of Grey Relational Coefficient (GRC) with the help of the empirical relation presented in equation 6 and the corresponding results are shown in Table 16.

$$
\xi_{\mathrm{i}}(\mathrm{k})=\frac{\Delta_{\mathrm{min}+} \zeta \Delta_{\max }}{\Delta_{\mathrm{oi}}(\mathrm{k})+\zeta \Delta_{\max }}
$$

where $\xi_{\mathrm{i}}(\mathrm{k})$ is the $\mathrm{GRC}, \mathrm{x}_{\mathrm{o}}(\mathrm{k})=1 ; \mathrm{k}=1,2, \ldots . \mathrm{m}$; for experimental responses, $\mathrm{x}_{\mathrm{i}}(\mathrm{k})$ is the original sequences; $\mathrm{i}=1,2, \ldots . .18$; experimental run; $\Delta_{\mathrm{oi}}(\mathrm{k})=\left\|\mathrm{x}_{\mathrm{o}}(\mathrm{k})-\mathrm{x}_{\mathrm{i}}(\mathrm{k})\right\|$; The difference of absolute value between $\quad \mathrm{x}_{\mathrm{o}}(\mathrm{k})$ and $\mathrm{x}_{\mathrm{i}}(\mathrm{k}), \zeta=$ distinguishing coefficient $(0.25)$, 
$\Delta_{\text {min }}=\forall \mathrm{j}^{\min } \epsilon \mathrm{i} \forall \mathrm{k}^{\min }\left\|\mathrm{x}_{\mathrm{o}}(\mathrm{k})-\mathrm{x}_{\mathrm{i}}(\mathrm{k})\right\|=$ smallest value of $\Delta_{\mathrm{oi}} ; \Delta_{\max }=\forall \mathrm{j}{ }^{\max } \epsilon \mathrm{i} \forall \mathrm{k}^{\max } \| \mathrm{x}_{\mathrm{o}}(\mathrm{k})$ $\mathrm{x}_{\mathrm{i}}(\mathrm{k}) \|=$ largest value of $\Delta_{\mathrm{oi}}$. After averaging the Grey relational grade can be determined as;

$$
\gamma_{i}=\frac{1}{n} \sum_{k=1}^{n} \xi_{i}(k)
$$

Where $n=$ number of responses. The $\mathrm{S} / \mathrm{N}$ ratios for corresponding values of GRG for all the responses are presented in Table 15. From the main effects plot for the means (Figure 6), it is elucidated that using CC with $0.5 \% \mathrm{CNT}$ at $60 \mathrm{~m} / \mathrm{min}$ ' $\mathrm{V}$ ' with ' $\mathrm{f}$ ' $0.131 \mathrm{~mm} / \mathrm{rev}$ and 'd' $0.5 \mathrm{~mm}$ would lead to optimum responses of $\mathrm{F}_{\mathrm{z}}, \mathrm{T}, \mathrm{T}_{\mathrm{w}}$ and $\mathrm{R}_{\mathrm{a}}$.

Table 14. Experimental results and its normalised values (Responses).

\begin{tabular}{lcccc|cccc}
\hline Exp & \multicolumn{4}{c|}{ Response } & \multicolumn{5}{|c}{ Normalised Responses } \\
No. & $\mathrm{T}$ & $\mathrm{F}$ & $\mathrm{R}_{\mathrm{a}}$ & $\mathrm{V}_{\mathrm{b}}$ & $\mathrm{T}$ & $\mathrm{F}$ & $\mathrm{R}_{\mathrm{a}}$ & $\mathrm{V}_{\mathrm{b}}$ \\
& $\left({ }^{\circ} \mathrm{C}\right)$ & $(\mathrm{N})$ & $(\mu \mathrm{m})$ & $(\mathrm{mm})$ & & & & \\
\hline 1 & 75 & 312.8 & 8.4 & 0.25 & 0.7083 & 0.9299 & 0.6250 & 0.8049 \\
2 & 96 & 363.4 & 10.2 & 0.42 & 0.4167 & 0.4922 & 0.1750 & 0.3902 \\
3 & 126 & 420.3 & 10.9 & 0.58 & 0.0000 & 0.0000 & 0.0000 & 0.0000 \\
4 & 75 & 335.4 & 7.8 & 0.25 & 0.7083 & 0.7344 & 0.7750 & 0.8049 \\
5 & 102 & 392.9 & 9.1 & 0.41 & 0.3333 & 0.2370 & 0.4500 & 0.4146 \\
6 & 89 & 341.4 & 8.3 & 0.49 & 0.5139 & 0.6825 & 0.6500 & 0.2195 \\
7 & 54 & 304.7 & 6.9 & 0.17 & 1.0000 & 1.0000 & 1.0000 & 1.0000 \\
8 & 71 & 357.4 & 7.6 & 0.42 & 0.7639 & 0.5441 & 0.8250 & 0.3902 \\
9 & 87 & 384.9 & 7.1 & 0.34 & 0.5417 & 0.3062 & 0.9500 & 0.5854 \\
10 & 93 & 394.7 & 9 & 0.49 & 0.4583 & 0.2215 & 0.4750 & 0.2195 \\
11 & 66 & 306.8 & 7.3 & 0.26 & 0.8333 & 0.9818 & 0.9000 & 0.7805 \\
12 & 86 & 351.9 & 9.3 & 0.44 & 0.5556 & 0.5917 & 0.4000 & 0.3415 \\
13 & 95 & 390.9 & 9.8 & 0.39 & 0.4306 & 0.2543 & 0.2750 & 0.4634 \\
14 & 83 & 331.1 & 8.7 & 0.46 & 0.5972 & 0.7716 & 0.5500 & 0.2927 \\
15 & 90 & 353.4 & 8.3 & 0.52 & 0.5000 & 0.5787 & 0.6500 & 0.1463 \\
16 & 84 & 358.4 & 10.6 & 0.54 & 0.5833 & 0.5355 & 0.0750 & 0.0976 \\
17 & 102 & 385.3 & 10.4 & 0.45 & 0.3333 & 0.3028 & 0.1250 & 0.3171 \\
18 & 85 & 334.3 & 10 & 0.54 & 0.5694 & 0.7439 & 0.2250 & 0.0976 \\
\hline
\end{tabular}

Mean of GRG is evaluated by taking the average of GRG for the respective experimental trials under the given conditions. The means thus obtained are shown in Table 16 for CNT. The optimal machining conditions to obtain excellent results are indicated here, and the order of their influence on responses is depicted below. The order in which they influence the output parameters is NPI, $\mathrm{d}, \mathrm{f}$ and V. ANOVA analysis of GRG for CNT disclose that \% contribution of each factor which is $35.19 \%, 34.32 \%$, $10.99 \%$ and $10.07 \%$ for NPI, $\mathrm{d}, \mathrm{V}$ and f respectively contribute to the least possible extent (Table 17). 
Table 15. Grey relational coefficient (GRC) and Grey grade values.

\begin{tabular}{|c|c|c|c|c|c|c|}
\hline \multirow{2}{*}{ Exp No. } & \multicolumn{4}{|c|}{ GRC } & \multirow{2}{*}{ Grey grade } & \multirow{2}{*}{$\mathrm{S} / \mathrm{N}$ ratio } \\
\hline & $\mathrm{T}$ & $\mathrm{F}$ & $\mathrm{R}_{\mathrm{a}}$ & $\mathrm{V}_{\mathrm{b}}$ & & \\
\hline 1 & 0.4615 & 0.7811 & 0.4000 & 0.5616 & 0.5511 & -5.1754 \\
\hline 2 & 0.3000 & 0.3299 & 0.2326 & 0.2908 & 0.2883 & -10.8031 \\
\hline 3 & 0.2000 & 0.2000 & 0.2000 & 0.2000 & 0.2000 & -13.9794 \\
\hline 4 & 0.4615 & 0.4849 & 0.5263 & 0.5616 & 0.5086 & -5.8725 \\
\hline 5 & 0.2727 & 0.2468 & 0.3125 & 0.2993 & 0.2828 & -10.9704 \\
\hline 6 & 0.3396 & 0.4405 & 0.4167 & 0.2426 & 0.3599 & -8.8764 \\
\hline 7 & 1.0000 & 1.0000 & 1.0000 & 1.0000 & 1.0000 & 0.0000 \\
\hline 8 & 0.5143 & 0.3542 & 0.5882 & 0.2908 & 0.4369 & -7.1924 \\
\hline 9 & 0.3529 & 0.2649 & 0.8333 & 0.3761 & 0.4568 & -6.8055 \\
\hline 10 & 0.3158 & 0.2431 & 0.3226 & 0.2426 & 0.2810 & -11.0259 \\
\hline 11 & 0.6000 & 0.9323 & 0.7143 & 0.5325 & 0.6948 & -3.1628 \\
\hline 12 & 0.3600 & 0.3798 & 0.2941 & 0.2752 & 0.3273 & -9.7011 \\
\hline 13 & 0.3051 & 0.2511 & 0.2564 & 0.3178 & 0.2826 & -10.9766 \\
\hline 14 & 0.3830 & 0.5226 & 0.3571 & 0.2611 & 0.3810 & -8.3815 \\
\hline 15 & 0.3333 & 0.3724 & 0.4167 & 0.2265 & 0.3372 & -9.4422 \\
\hline 16 & 0.3750 & 0.3499 & 0.2128 & 0.2169 & 0.2886 & -10.7941 \\
\hline 17 & 0.2727 & 0.2639 & 0.2222 & 0.2680 & 0.2567 & -11.8115 \\
\hline 18 & 0.3673 & 0.4940 & 0.2439 & 0.2169 & 0.3305 & -9.6166 \\
\hline
\end{tabular}

Table 16. Response table for means of Grey grades

\begin{tabular}{lcccc}
\hline \multirow{2}{*}{ Levels } & & \multicolumn{2}{c}{ Factors } & \\
\hline 1 & Nanoparticle & $\mathrm{V}$ & $\mathrm{f}$ & DOC \\
2 & 0.3465 & 0.4853 & 0.4675 & 0.5529 \\
3 & 0.3838 & 0.3901 & 0.4186 & 0.3645 \\
4 & 0.6312 & 0.3353 & 0.3246 & 0.2933 \\
5 & 0.4344 & -- & -- & -- \\
6 & 0.3336 & -- & -- & -- \\
Delta & 0.2919 & -- & -- & -- \\
Rank & 0.3393 & 0.1500 & 0.1430 & 0.2596 \\
Optimum & 1 & 3 & 4 & 2 \\
\hline
\end{tabular}

Table 17. ANOVA for Grey grades

\begin{tabular}{lccccc}
\hline Factors & DOF & $\begin{array}{c}\text { Sum of } \\
\text { squares }\end{array}$ & $\begin{array}{c}\text { Mean } \\
\text { squares }\end{array}$ & $\begin{array}{c}\text { Variance } \\
\text { ratio }\end{array}$ & \% contribution (P) \\
\hline \% Nanoparticle & 5 & 0.2214 & 0.0443 & 4.48 & 35.19 \\
Cutting speed & 2 & 0.0692 & 0.0346 & 3.50 & 10.99 \\
Feed & 2 & 0.0634 & 0.0317 & 3.21 & 10.07 \\
Depth of cut & 2 & 0.2159 & 0.1079 & 10.93 & 34.32 \\
Error & 6 & 0.0593 & 0.0099 & & 9.43 \\
Total & 17 & 0.6291 & & & 100.00 \\
\hline
\end{tabular}




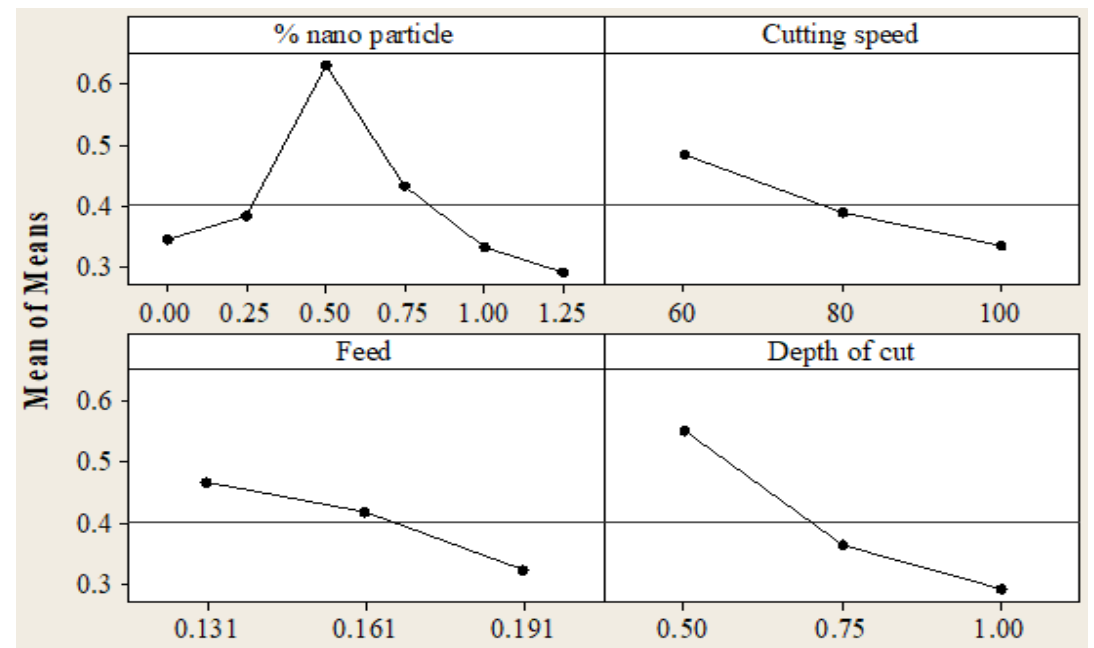

Figure 6. Main effects plot of means for Grey grade.

\section{CONCLUSION}

This work emphasises the estimation of basic properties of nano cutting fluids prepared from vegetable oil, its viability and their performance in machining of AISI 1040 steel. Experiments are performed under various cutting fluid environments like dry, flood and MQL. The following conclusions are drawn from the results.

i. Density, dynamic viscosity, thermal conductivity and coefficient of heat transfer of CNT dispersed nanofluids increase with an increase in nanoparticle inclusions for all the cases considered.

ii. Specific heat of CNT nanofluids slightly decreased with an increase in cutting fluids with nanoparticle inclusions.

iii. Initial machining was done at constant cutting conditions, $0.25 \% \mathrm{CNT}$ in dry, flood and MQL modes. MQL executed well to reduce nodal temperatures and cutting forces, and thus improved tool life and surface quality.

iv. From the perspective of machining performance, CNT dispersed cutting fluids with $0.5 \%$ NPI applied at $60 \mathrm{~m} / \mathrm{min}, 0.131 \mathrm{~mm} / \mathrm{rev}$ and $0.5 \mathrm{~mm}$ outcome as better one. The depth of cut is more influential by $85 \%$ for CNT dispersed fluids in obtaining minimum cutting forces, followed by other input parameters. In similar lines, the contribution of DOC is influential by $45 \%$ on cutting temperatures.

v. The contribution of NPI for minimum tool wear is $29.16 \%$. Similarly, it is found to be $69.9 \%$ for surface roughness, and other parameters followed.

vi. The same conditions (V: $60 \mathrm{~m} / \mathrm{min}, \mathrm{f}: 0.131 \mathrm{~mm} / \mathrm{rev}, \mathrm{d}: 0.5 \mathrm{~mm}$ and $0.5 \% \mathrm{NPI}$ ) are observed to strike optimum machining performance as observed from Taguchi based GRA technique.

vii. The order of influence of parameters is NPI, depth of cut, cutting speed and feed on machining performance. Influence of NPI is $35.19 \%$ on $\mathrm{F}, \mathrm{T}, \mathrm{V}_{\mathrm{b}}$ and $\mathrm{R}_{\mathrm{a}}$ according to GRA analysis.

viii. Microbial contamination is found to increase with time for all the samples considered. It is found to be least at $0.25 \%$ NPI for CNT dispersed fluids. BOD and COD indices are increased with an increase in nanoparticle inclusions. The fluids are biodegradable and can be treated biologically for disposal. 


\section{ACKNOWLEDGEMENT}

Support from the DST-SERB fast-track scheme for young scientists (Grant No. SB/FTP/ETA-269/2011) is gratefully acknowledged.

\section{REFERENCES}

[1] Chiou RY, Chen JSJ, Lu L, North MT. The effect of an embedded heat pipe in a cutting tool on temperature and wear. Proceedings of ASME Conference on Mechanical Engineering, pp. 1-8; 2003.

[2] Sukaylo V, Kaldos A, Pieper HJ, Bana V, Sobczyk M. Numerical simulation of thermally induced workpiece deformation in turning when using various cutting fluid applications. Journal of Materials Processing Technology 2005; 167: 408-414.

[3] Ko TL, Kim HS, Chung BG. Air-oil cooling method for turning of hardened material. International Journal of Advanced Manufacturing Technology 1999: 15(7); 470-477.

[4] Bianchi EC, Franzo CG, De Aguiar PR, Catai RE. Analysis of the influence of infeed rate and cutting fluid on cylindrical grinding processes using a conventional wheel. Journal of Materials Research 2004: 7(3); 385-392.

[5] Prevention of skin problems when working with metal working fluids. safety and health assessment \& research for prevention. Washington State Department of Labor and Industries. Technical Report: 2001.

[6] Chazal PM. Pollution of modern metalworking fluids containing biocides by pathogenic bacteria in France re-examination of chemical treatments accuracy. European Journal of Epidemiology 1995: 11(1); 1-7.

[7] Raynor PC, Kim SW, Bhattacharya M. Mist generation from metalworking fluids formulated using vegetable oils. Annals of Occupational Hygiene 2005: 49(4); 283293.

[8] Ngoi BKA, Sreejith PS. Dry machining: machining of the future. International Journal of Materials Processing Technology 2000: 101; 287-291.

[9] Baradie MAEI. Cutting fluids: Part II. Recycling and clean machining. Journal of Material Processing Technology 1996: 56; 798-806.

[10] Ojolo SJ, Amuda MOH, Ogunmola OY, Ononiwu CU. Experimental determination of the effect of some straight biological oils on cutting force during cylindrical turning. Revista Matéria 2008: 13(4); 650 - 663.

[11] Diniz AE, Micaroni R. Cutting conditions for finish turning process aiming: the use of dry cutting, International Journal of Machine Tools and Manufacture 2002: 42(8); 899-904.

[12] Hanyu H, Kamiya S, Murakami Y, Saka M. Dry and semi-dry machining using finely crystallized diamond coating cutting tools. Surface and Coatings Technology 2003: 173-174; 992-995.

[13] Padmini R, Vamsi KP, Krishna MRM. Effectiveness of vegetable oil based nanofluids as potential cutting fluids in turning AISI 1040 steel. Tribology International 2016: 94; 490-501.

[14] Vamsi KP, Srikant RR, Padmini R, Bharat P. Basic properties and performance of vegetable oil-based boric acid nanofluids in machining. In: Sathiyamoorthy S., Caroline B., Jayanthi J. (eds) Emerging trends in science, engineering and technology. Lecture notes in mechanical engineering, India: Springer, 2012, p 197206. 
[15] Sodavadia KP, Makwana AH. Experimental investigation on the performance of coconut oil based nano fluid as lubricants during turning of AISI 304 austenitic stainless steel. International Journal of Advanced Mechanical Engineering 2014: 4(1); 55-60.

[16] Hegab H, Kishawy HA, Gadallah MH, Umer U, Deiab I. On machining of Ti-6Al$4 \mathrm{~V}$ using multi-walled carbon nanotubes-based nano-fluid under minimum quantity lubrication. The International Journal of Advanced Manufacturing Technology 2018; 97:1593-1603.

[17] Hegab H, Umer U, Soliman M, Kishawy HA. Effects of nano-cutting fluids on tool performance and chip morphology during machining Inconel 718. The International Journal of Advanced Manufacturing Technology 2018; 96: 3449-3458.

[18] Yimin X, Qiang L. Heat transfer enhancement of nanofluids. International Journal of Heat and Fluid Flow 2000; 21: 58-64.

[19] Krajnik P, Pusavec F, Rashid A. Nanofluids: properties, applications and sustainability aspects in materials processing advances in sustainable manufacturing. Springer link. 2011: 107-113.

[20] Rahman SS, Ashraf MZI, Amin AN, Bashar MS, Ashik MFK, Kamruzzaman M. Tuning nanofluids for improved lubrication performance in turning biomedical grade titanium alloy. Journal of Cleaner Production 2019; 206:180-196.

[21] Fadhillahanafi NM, Leong KY, Risby MS. Stability and thermal conductivity characteristics of carbon nanotube based nanofluids. International Journal of Automotive and Mechanical Engineering. 2013:8; 1376-1384.

[22] Brown A. Benson's microbiological applications: laboratory manual in general microbiology, short version. McGraw-Hill HigherEducation; 2007.

[23] Amrita M, Srikant RR, Sitaramaraju AV, Prasad MMS, Krishna PV. Environmental aspects of nano cutting fluids. In: Proceedings of the National Conference on Latest Innovations in Mechanical Engineering (LIME), pp. 47-51; 2013.

[24] Rapeti P, Pasam VK, Gurram KM, Revuru RS. Performance evaluation of vegetable oil based nano cutting fluids in machining using grey relational analysisA step towards sustainable manufacturing. Journal of Cleaner Production 2018: 172 (20); 2862-75. 